\title{
Assessment of Functional Outcome of Bicolumnar Dual Plating for Bicondylar Fractures of Tibial Plateau
}

\author{
Shrestha $\mathrm{DK}^{1}, \mathrm{KC} \mathrm{D}^{1}$, Karki $\mathrm{P}^{1}$, Shrestha $\mathrm{S}^{1}$, Yogi $\mathrm{S}^{1}$
}

\begin{abstract}
Introduction: Operative treatment of bicondylar fractures of tibial plateau is challenging and controversial. Aims: The aim of this study is to reveal the functional outcome of it by using bicolumnar dual plates and screws. Methods: This is a prospective hospital based interventional study carried out in the department of Orthopaedics of Nepalgunj Medical College Teaching Hospital. Thirty two Schatzker type V or AO (Association of Osteosynthesis) type 41 C1 \& C2 fractures were treated between January 2016 and December 2019 with bicolumnar dual plating. The functional clinical outcomes were analyzed and evaluated using modified Rasmussen score. Results: Thirty two patients were included in the study. Out of which twenty four were male and eight were female. Average age was 32.21 years, eighteen were right sided and fourteen were left sided. Duration of surgery was 106 mins (range 90-120 mins) and the average duration of hospitalization was 7.81 days (range 4-14 days). Five patients of impending compartment syndrome and three patients with common peroneal nerve palsy were managed conservatively and also were included in the study. Two patients with superficial wound infection needed minimal debridement. One patient had varus angulation of $10^{\circ}$ at third follow up after he fell from bed but surgical intervention were not needed. All fractures united. The average time for fracture healing was 21.5 weeks (range 16-32 weeks). At the Eighteen months follow up, the average knee range of motion was $131^{\circ}\left(\right.$ range $\left.110^{\circ}-140^{\circ}\right)$. The functional outcome were evaluated using modified Rasmussen scoring system, which was 27.34 (range 22-30). Conclusion: Bicolumnar dual plating for bicondylar fractures of tibial plateau can provide excellent and stable fixation allowing early range of motion and gives excellent to good functional outcome.
\end{abstract}

Keywords: Bicolumnar dual plating, Bicondylar fracture, Tibial plateau

Authors:

1. Dr. Dinesh Kumar Shrestha

2. Dr. Dipendra KC

3. Dr. Prateek Karki

4. Dr. Sabin Shrestha

5. Dr. Sushil Yogi

${ }^{1}$ Department of Orthopedics, Nepalgunj Medical College and Teaching Hospital, Kohalpur, Banke

\section{Address for Correspondence:}

Dr. Dinesh Kumar Shrestha

Associate Professor

Department of Orthopedics

Nepalgunj Medical College and Teaching Hospital

Kohalpur, Banke

Email: dr_dineshstha@yahoo.com

\section{INTRODUCTION}

Tibial plateau fractures are increasing in incidence and constitute $1.2 \%$ of all fractures. ${ }^{1}$ These fractures occurs by a combination of axial compression together with a valgus or varus force. It often occurs in elderly over sixty years due to fall at the same level but in young adult due to road traffic accidents and fall from heights. ${ }^{2}$ For tibial plateau fractures Schatzker classification is the widely used to assess the initial injury, plan management and predict the prognosis. It classifies the tibial plateau fractures into six types: Type I-wedge shaped fracture of the lateral tibial plateau, Type-II-splitting and depression of the lateral tibial plateau, Type-III-pure depression of the lateral tibial plateau Type-IV-medial tibial plateau fracture with a split or depressed component,Type-V-wedge fractures of both lateral and medial tibial plateau and Type-VI-transverse tibial metadiaphyseal fracture, along with any type of tibial plateau fracture. ${ }^{3}$ Among them type $\mathrm{V}$ and $\mathrm{VI}$ are complex fractures which is very often associated with soft tissue injury, risk of wound dehiscence, difficulty in intraoperative reduction and difficulty in sufficient fixation of fractures. Another common classification is the AO (Association of Osteosynthesis) system which includes three main groups a) extra articular b) partial articular and c) complete articular fractures which is further divided into subgroups. However, there is no effective surgical management but the treatment options include screws, Ilizarov ring fixation, Hybrid external fixation, bicolumnar or dual buttress plating, unilateral locking plate etc. ${ }^{4}$ This study 
aims to evaluate the anatomical and functional outcome of bicolumnar dual plating in bicondylar fractures of tibial plateau.

\section{METHODS}

This was a prospective hospital based interventional study was carried out in the department of Orthopaedics of Nepalgunj Medical College Teaching Hospital, Kohalpur, from January 2016 to December 2019. Non-probability purposive sampling technique was used to scrutinize total thirty two patients ranging from age eighteen to fifty two years. Ethical permission was obtained from the Institutional review Committee of Nepalgunj Medical College Teaching Hospital Kohalpur. Informed consent was being pertained to maintain the confidentiality of the patients. Patients with close Schatzker type $\mathrm{V}$ fractures or AO type $41 \mathrm{C}_{1}$ and $41 \mathrm{C}_{2}$, age group 18-52 years and those patients willing to be involved in the study were included whereas Schatzker type I, II, III, IV and VI fractures or AO type $41 \mathrm{C}_{3}$, old fractures at tibial plateaus, tibial plateau fractures with compartment syndrome, tibial plateau fractures with injuries to the knee stabilizers and patients with systemic illnesses were excluded from the study. All the patients were admitted from Emergency by the Orthopaedic surgeons, adequate $x$-ray imaging with Anteroposterior, lateral, oblique views and 3D CT scan of the knee joint were taken for proper diagnosis and to know the degree of comminution and articular involvement. MRI was also recommended to 12 patients who has been suspected for soft tissue injuries associated with these fractures. All the patients were explained well about the procedure. Fractures were graded preoperatively using the Schatzker's and AO classification of tibial plateau. The limb was elevated and calcaneal pin traction was applied on BohlerBraun splint with $3-5 \mathrm{~kg}$ of weight for minimum of 3 days for the resolution of oedema and the fracture blisters and appearance of skin wrinkles. No anterior knee spanning external fixator were used.

\section{Operative procedure:}

Patients were operated on a radiolucent table under regional or general anaesthesia with a knee flexion of $15-20^{\circ}$. Tourniquet was used for all the surgeries. We fixed the medial plateau first but if there were severe comminution on the medial side then only we did lateral plateau fixation first. A sand bag was placed under the contralateral hip before posteromedial fixation and was removed during anterolateral fixation. A curvilinear incision $1 \mathrm{~cm}$ posterior from posteromedial border of proximal tibia was made curving along the distal portion of the pes anserinus tendons. The saphenous vein and nerve were identified and retracted anteriorly. The deep fascia was incised to reveal the pes anserinus and the medial gastrocnemius muscle. The gutter was created between the pes anserinus tendons by retracting it anteriorly and the medial gastrocnemius and popliteus muscle by retracting it posteriorly. T-buttress plates were used after proper reduction and temporary fixation with k- wires. Wound was closed in layers with drain in situ.

Simultaneously after the posteromedial fixation initial sand bag was removed from the contralateral hip and it was placed beneath the ipsilateral hip. Another curvilinear anterolateral incision was made over the proximal lateral tibia over Gerdy's tubercle. The fascia was divided longitudinally extending proximally and distally. Exposure of the lateral surface of proximal tibia was performed with a periosteal elevator. Sub meniscal arthrotomy was done in depressed articular surface where needed. Reduction was done by longitudinal traction by the assistant. Temporary Kirschner wires were used to maintain the reduction which was confirmed using image intensifier. Kirschner wires were placed in such a way that later on it was replaced by the screw hole of desired precontoured locking plates. Wound closed in layers with drain in situ. Knee was immobilized in a long knee brace for two weeks and knee range of motion were encouraged from the $3^{\text {rd }}$ postoperative day.

The clinical results were evaluated using the modified Rasmussen clinical score, the patients were asked regarding the degree of pain, distance that they are able to walk, getting up from the floor and squat or to do activities of daily living, total range of motion, stability in flexion and extension and the power of quadriceps. The scores were graded as poor $(<20)$, fair (20-23), good (24-27) and excellent (28-30).

\section{RESULTS}

Our study comprised of 32 patients with Type $V$ Schatzker or $\mathrm{AO} 41 \mathrm{C}_{1}$ and $\mathrm{C}_{2}$ tibial plateau fractures, including twentythree41 $C_{1}$ cases $(71.87 \%)$ and nine $C_{2}$ cases $(28.12 \%)$ with an average age of 32.21 years (ranging from $18-52$ years).Among them 24 were male and 8 were female patients.

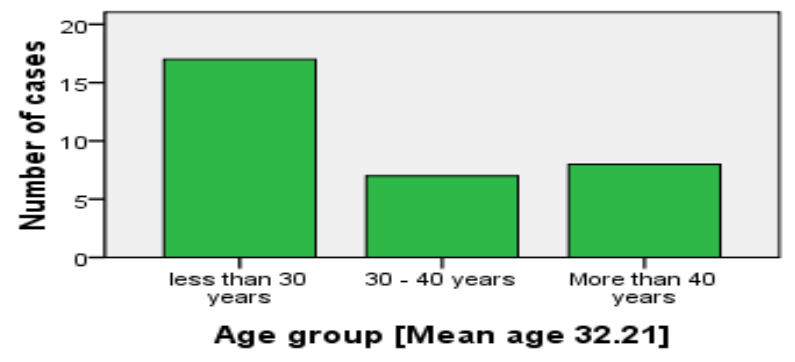

Figure 1: Total number of cases showing in different age group

All the injuries were a result of fall from height 14 (43.75\%) cases, road traffic accident 7 (21.87\%) cases, automobile pedestrian accident $5(15.62 \%)$ cases and sports related injuries $6(18.75 \%)$ cases. Five(15.62\%) patients with impending compartment syndrome were immediately addressed with cold packs and elevation in Bohler Braun splint with bed end raise. Vigorous monitoring was done but fortunately they were not needed emergency fasciotomy.3 (9.37\%) Patients with common peroneal nerve palsy were identified during admission at emergency and were given foot drop splints which were recovered at around four months of follow up. 


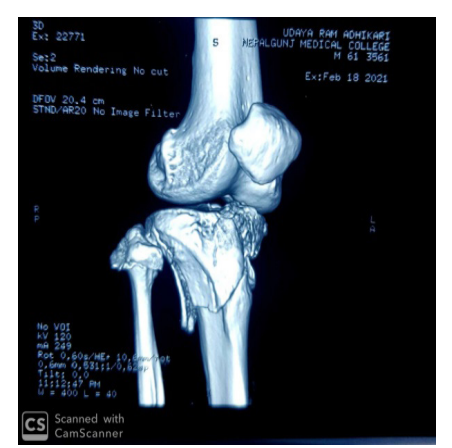

Fig: i

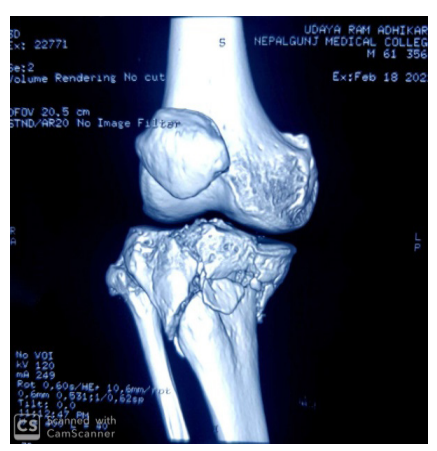

Fig: ii
Figure 2: Preoperative 3D CT view

We found $2(6.25 \%)$ obese patients with superficial wound infection which were resolved by minimal debridement and intravenous antibiotics but they needed prolong hospital stay of 9 and 14 days. Out of 32 patients, all other regained good range of motion except $1(3.12 \%)$ patient, who had fallen accidentally from a two tier bed occurring secondary fracture displacement in the form of Varus angulation of $10^{\circ}$ on 3 rd follow up i.e., 16 weeks after surgery, but no secondary surgery were planned.



Figure 3: Pre-operative X-ray in AP and Lateral View

All patients underwent surgery within 48-72 hours of injury. They were fixed with dual bicolumnar plating, which consists of a combination of precontoured anterolateral buttress locking plate and posteromedial buttress locking plate of $4.5 \mathrm{~mm}$ system. The average operation time was 106 mins (range 90120 mins) and the average duration of hospital stay was 7.8 days (range 4-14 days).Postoperatively Knee movement was started from the 3rd day. Partial weight bearing was started after 8 weeks and full weight bearing at 16 weeks.

\begin{tabular}{|c|c|c|c|c|c|}
\hline & Minimum & Maximum & Mean & $\begin{array}{c}\text { Std. } \\
\text { Deviation } \pm\end{array}$ & $P$ value \\
\hline $\begin{array}{l}\text { Time for } \\
\text { fracture healing } \\
\text { in weeks }\end{array}$ & 16.0 & 32.00 & 21.50 & 4.39 & \\
\hline $\begin{array}{l}\text { Range of } \\
\text { motion in } \\
\text { degree }\end{array}$ & $0-110$ & 140 & 5.25 & 1.54 & \\
\hline & & & & & 0.85 \\
\hline
\end{tabular}

Table I: Association between time of fracture healing and range of motion range of knee motion was $131.09^{\circ}$. The range of movement varied from $110^{\circ}-140^{\circ} .29$ patients $(90.62 \%)$ had no lack of extension ,but 2 patients (6.25\%) had lack of extension of $10^{\circ}$ and 1 patient $(3.12 \%)$ had lack of extension of $5^{\circ} .8$ patients $(25 \%)$ had knee range of motion of atleast $140^{\circ} .7$ Patients $(21.87 \%)$ had range of motion of $135^{\circ}, 8$ Patients $(25 \%)$ had $130^{\circ}, 5$ patients $(15.62 \%)$ had $125^{\circ}, 2$ patients $(6.25 \%)$ had $120^{\circ}, 1$ patient had $115^{\circ}$ and 1 patient (3.12\%) had range of motion of $110^{\circ}$. Hospital stay varied from 4-14 days (mean 7.8 days). All our patients had union in 21.5 weeks (range from 16-32 weeks). All our patients had union in 21.5 weeks (range from 16-32 weeks). Hence, the range of motion and time for fracture healing was insignificant association between these two variables. Functional outcome of our patients was graded by using the six parameters of modified Rasmussen scoring system like pain, walking capacity, knee extension, Range of motion, Stability of knee joint and power of the quadriceps. Out of 32 bicondylar fractures of tibial plateau 15 patients $(46.87 \%)$ had excellent outcome, 13 patients $(40.62 \%)$ had good outcome, 3 patients $(9.37 \%)$ had fair outcome and 1 patient (3.121\%) had poor outcome.

\begin{tabular}{cccccc}
$\begin{array}{c}\text { Time for } \\
\text { fracture } \\
\text { healing in } \\
\text { weeks }\end{array}$ & $\begin{array}{c}\text { Secondary } \\
\text { displacement }\end{array}$ & ICS & CPN & $\begin{array}{c}\text { Complications } \\
\text { dehiscence }\end{array}$ & $\begin{array}{c}\text { No } \\
\text { complication }\end{array}$ \\
\hline 16 & 0 & 2 & 2 & 0 & 5 \\
\hline 2 & 0 & 1 & 0 & 1 & 5 \\
\hline 24 & 1 & 2 & 1 & 2 & 9 \\
32 & 0 & 0 & 0 & 0 & 2 \\
\hline
\end{tabular}

Table II: Distribution of postoperative complication according to time taken for fracture healing

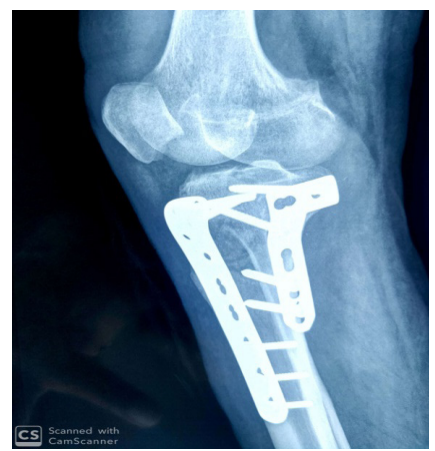

Fig. iii. Lateral view



Fig iv. AP view
Figure 4: $X$ rays showing the post-operative status

All were followed up for at least 18 months. The average 
Modified Rasmussen scoring system

\begin{tabular}{|c|c|}
\hline Pain & Points \\
\hline None & 6 \\
\hline Occasional Pain & 5 \\
\hline Stabbing pain in certain positions & 3 \\
\hline Constant Pain after activity & 1 \\
\hline Significant rest pain & -3 \\
\hline \multicolumn{2}{|l|}{ Walking capacity } \\
\hline $\begin{array}{l}\text { Normal walking capacity (in relation } \\
\text { to age) }\end{array}$ & 6 \\
\hline Walking outdoors (>1h) & 5 \\
\hline Walking outdoors (<15 min-1h) & 3 \\
\hline Walking outdoors (<15 min) & 1 \\
\hline Walking indoors only & 0 \\
\hline Wheelchair / bedridden & -3 \\
\hline \multicolumn{2}{|l|}{ Knee Extension } \\
\hline Normal & 4 \\
\hline Lack of extension $(<100)$ & 2 \\
\hline Lack of extension (>100) & 0 \\
\hline Lack of extension (>200) & -2 \\
\hline \multicolumn{2}{|l|}{ Total range of motion } \\
\hline Full & 6 \\
\hline At least 1200 & 5 \\
\hline At least 900 & 3 \\
\hline At least 600 & 1 \\
\hline$\geq 600$ & -3 \\
\hline \multicolumn{2}{|l|}{ Stability } \\
\hline $\begin{array}{l}\text { Normal stability in extension and } \\
200 \text { of flexion }\end{array}$ & 6 \\
\hline $\begin{array}{l}\text { Abnormal instability } 200 \text { of } \\
\text { flexion }\end{array}$ & 4 \\
\hline Instability in extension $(<100)$ & 2 \\
\hline Instability in extension (> 100) & 0 \\
\hline \multicolumn{2}{|l|}{ Power of quadriceps } \\
\hline Grade 5 & 2 \\
\hline Grade 3-4 & 1 \\
\hline Grade $<3$ & 2 \\
\hline Maximum & 30 \\
\hline Excellent & 28- 30 \\
\hline Good & $24-27$ \\
\hline Fair & $20-23$ \\
\hline Poor & $<20$ \\
\hline
\end{tabular}

\section{DISCUSSION}

Treatment of complex tibial plateau fracture is still controversial and there is no consensus about the optimal surgical technique despite of improved surgical techniques and variety of fixation system..$^{5} \mathrm{~A}$ bicolumnar dual plating technique using posteromedial approach combined with an anterolateral approach has been suggested by several authors. ${ }^{6}$ The Canadian Orthopedic Trauma Society reported 20\% deep wound infection in the patient treated with bicolumnar dual plating osteosynthesis. ${ }^{7} \mathrm{Uhl}$ et $\mathrm{al}^{8}$ reported high rates of skin infection and osteomyelitis in $42 \%$ and $23 \%$ of patients treated with dual plates. Barei et al (2004) reported of $8.4 \%$ deep infection rate in 83 patients treated with bicolumnar plating for bicondylar fractures of tibial plateau. ${ }^{9}$ In our study $6.25 \%$ of cases had superficial infection but no patient had significant deep infection and they were not required implant removal prior to bony union.Literature shows around $20 \%$ of patient are likely to develop wound infection requiring unplanned secondary procedures. ${ }^{10}$ A prolonged duration of surgery and a prolonged use of tourniquet are related to an increased risk of surgical site infection after bicolumnar dual plating of the tibial plateau. ${ }^{11}$ In our study average operation time was 106 mins (range 90-120 mins) which may be one of the important reasons for the low surgical site infection rates.

Yoo et al reported the inability of the single lateral locked plate to fix posteromedial fragments, requiring additional medial plate. ${ }^{12}$ Chang et al reported that the single lateral locking plate takes less surgical time, less skin necrosis but higher rate of loss of reduction. ${ }^{13}$ We did bicolumnar dual plating using locking plates and screws of $4.5 \mathrm{~mm}$ on anterolateral side and $3.5 \mathrm{~mm}$ on posteromedial side in all our cases regardless of any age. There were no loss of reduction or fracture displacement except in one case who had a Varus angulation of $10^{\circ}$ on 16 weeks of follow up, after he hell from the bed, but no secondary surgery were planned to him. Literature shows that loss of reduction is common about $30-79 \%$ in age group more than 60 years due to premature weight bearing, osteoporosis, comminution and significant initial displacement. ${ }^{14}$ There have been various devices which advocates for good fixation such as intramedullary nailing and condylar bolts ${ }^{15}$, single locking plate, Ilizarov fixators or hybrid constructs also have been used in bicondylar tibial plateau fractures. ${ }^{16}$

\section{LIMITATIONS}

Our study has some limitations such as small sample size $(n=32)$, though sample size above 30 is considered and statistically adequate. However, the follow up is short term (18 months) and the maximum age of the patient is 52 years. Long term follow up may reveal post traumatic arthritic changes whereas including geriatric population more than 60 years in the study may reveal the cases of implant failure or the need of other supplementary fixation devices; further prospective randomized control trials are needed to confirm the value of this operative procedure.

\section{CONCLUSION}

Bicondylar fractures of tibial plateau are challenging and difficult to manage. Bicolumnar dual plating through medial and lateral approaches is encouraging with minimal complications. The functional outcome of dual plating at 18 months of follow up is excellent to good according to Rasmussen criteria in most 
of the cases. Bicolumnar plating may be considered as one of the best option for bicondylar fractures of tibial plateau.

\section{REFERENCES}

1. Schatzker J, Watson JT, Levy B, Cole P Tibial plateau fractures. In: Browner, Jupiter, Levine, Trafton, editors. Skeletal trauma; 2009.

2. Moore TM, Patzakis MJ, Harvey JP.Tibial plateau fractires: definitions, demographics, treatment rationale, and long term results of closed traction management or operative reduction. J Orthop Trauma. 1987;1(2):97-119.

3. Schatzker J, McBroom R, Bruce D. The tibial plateau fracture: The Toronto experience 1968-1975.Clin Orthop Relat Res.1979;(138):94-104.

4. Cole P, Levy B, Schatzker J, Watson JT: Tibial plateau fractures. Skeletal Trauma: Basic Science Management and Reconstruction. Saunders Elsevier, Philadelphia; 2009. 10.1016/B978-1-4160-2220-6.10056-8.

5. Koval KJ, Helfet DL. Tibial plateau fractures: evaluation and treatment. J Am Acad Orthop Surg. 1995 Mar;3(2):86-94.

6. Barei DP, O'Mara TJ, Taitsman LA, et al. Frequency and fracture morphology of the posteromedial fragment in bicondylar tibial plateau patterns. J Ortho Trauma. 2008;22:176-182.

7. Mckee MD, Pitrani SP, Stephen DJ.The Canadian Orthopedic Trauma Society, Open reduction and internal fixation compared with circular fixator application for bicondylar tibial plateau fractures. Results of a multicenter, prospective, randomized clinical trial. J Bone joint Surg Am.2006;88:261323.

8. Uhl RL, Goldstock L, Carter AT, Lozman J, New Orleans, Louisiana: Presented at the 61st AAOS meeting; 1994. Hybrid external fixation for bicondylar tibial plateau fractures.

9. Barei DP, Nork SE, Mills WJ, Henley MB and Benirschke SK. Complications associated with internal fixation of highenergy bicondylar tibial plateau fractures utilizing a twoincision technique. J Orthop Trauma 2004;18(10): 649-657.

10. Colman M, Wright A, Gruen G, Siska P, Pape HC, Tarkin I. Prolonged operative time increases infection rate in tibial plateau fractures. Injury 2013;44(2):249-252.

11. Gamavos C. Retropatellar nailing and condylar bolts for complex fractures of the tibial plateau: technique, pilot study and rationale. Injury. 2014 Jul;45(7):1099-104.

12. Yoo BJ, Beingessner DM, Barei DP. Stabilization of the posteromedial fragment in bicondylar tibial plateau fractures: a mechanical comparison of locking and nonlocking single and dual plating methods. J trauma. 2010;69(1):148-55.

13. Chang $H$, Zhu Y, Zheng Z, Chen W, Zhao S, Zhang Y, et al. Meta-analysis shows that highly comminuted bicondylar tibial plateau fractures treated by single lateral locking plate give similar outcomes as dual plate fixation. Int Orthop. 2016;40(10):2129-41.
14. Gaudinez RF, Mallik AR, Szporn M, Hybrid external fixation of comminuted tibial plateau fractures. Clin Orthop Relat Res. $1996 \mathrm{Jul} ; 328: 203-10$.

15. Mallik AR, Covall DJ. Whitelaw GP. Internal versus external fixation of bicondylar tibial plateau fractures. Orthop Rev. 1992 Dec;21(12):1433-6.

16. Canadian Orthopaedic Trauma Society. Open reduction and internal fixation compared with circular fixator application for bicondylar tibial plateau fractures. Results of a multicenter, prospective, randomized clinical trial. J Bone Joint Surg Am. 2006 Dec;88(12):2613-23. 